\title{
5 Research Square

\section{IL-7R and CCR7 Regulate Distinct Metabolic \\ Pathways in Naïve T Cells to Promote T Cell Motility}

Janie R Byrum

University of New Mexico Health Sciences Center

Rebekah Gridley

University of New Mexico

David J Torres

Northern New Mexico College

Paulus Mrass

University of New Mexico Health Sciences Center

Sreenivasa Rao Oruganti

University of New Mexico Health Sciences Center

Judy L Cannon ( $\nabla$ jucannon@salud.unm.edu )

University of New Mexico Health Sciences Center

\section{Research Article}

Keywords: Imaging the immune system, immunometabolism, interleukin-7, chemokines, CCR7

Posted Date: March 1st, 2022

DOI: https://doi.org/10.21203/rs.3.rs-1382260/v1

License: (c) (i) This work is licensed under a Creative Commons Attribution 4.0 International License.

Read Full License 


\section{Abstract}

Naïve T cells movement through tissues, including through lymph nodes, requires ongoing energy supply for rapid motility promoting $T$ cell scanning of dendritic cells and T cell activation. Rapid movement is facilitated by signaling through chemokine receptor CCR7, but how signaling to motility relates to T cell metabolism is not well understood. Conversely, whether signals including IL-7R which are known to regulate naïve T cell metabolism might impact motility is not known. We analyze how CCR7 and IL-7R regulate $T$ cell motility and metabolism. Using Seahorse analysis, we find that CCL21 signaling to CCR7 decreases oxidative phosphorylation, but has no effect on glycolysis. In contrast, IL-7 promotes glycolysis but shows no effect on respiration. We demonstrate a previously unidentified role for IL-7/IL-7R in promotion of $\mathrm{T}$ cell motility in lymph nodes by imaging $\mathrm{T}$ cell movement in lymph nodes after inhibition of IL-7R and IL-7. Downstream of IL-7R, JAK3 and STAT5, but not mTOR, mediates rapid motility. Our results shed new light on how metabolism intersects with motility to promote more efficient $\mathrm{T}$ cell movement within lymph nodes to promote potential for DC scanning and interaction, potentially through differential means of ATP production.

\section{Introduction}

Immunometabolism is increasingly recognized as a key determinant for immune cell function and immune responses (1). Immunometabolic changes in T cells have been shown to be crucial for $\mathrm{T}$ cell responses throughout different stages of $\mathrm{T}$ cell activation $(2,3)$. Naïve and memory $T$ cells are thought to predominantly utilize catabolism via the oxidative phosphorylation (OXPHOS) pathway to generate ATP while activated T cells have been shown to use glycolysis, known as the Warburg effect $(2,4)$.

A major metabolic need for naïve T cells is movement to and within lymph nodes. Movement into and through tissue is fundamental for $T$ cell function in search of cognate antigen leading to activation and effector functions (5-7). Migration depends on a continuous supply of energy, yet metabolic pathways that provide energy required for movement remain incompletely understood. Naïve T cells move into lymph nodes by transendothelial migration and then within the T cell zone of the lymph node apparently randomly with directional persistence and a lognormal distribution of step sizes in order to make contact with dendritic cells $(7,8)$. The chemokine CCL21 binding to CCR7 on naïve T cells is a key regulator of T cell migration into lymph nodes and chemokinesis in the paracortex of lymph nodes $(9,10)$. CCL21 is produced by lymph node stromal cells signaling to CCR7, a G-protein-coupled receptor to induce high speed T cell motion $(11,12)$. How CCR7 might regulate metabolic function leading to $T$ cell motility has not been investigated.

The major cytokine that regulates naïve T cell homeostasis including development and survival is Interleukin 7 (IL-7). IL-7 is predominantly produced by fibroblastic reticular cells (FRCs) in lymph nodes to support T cell homeostasis (13) and drive LN architecture remodeling (14). IL-7 binds IL-7R which mediates signaling via the JAK/STAT signal transduction pathway leading to survival and proliferation of naïve T cells $(15,16)$. IL-7R has also been shown to signal via key metabolic regulators mTOR and 
PI3K/Akt $(17,18)$. Interestingly, while naïve T cells are thought to use OXPHOS predominantly, IL-7 has been shown to regulate glycolysis for homeostasis $(18,19)$. It is not known whether IL-7 might also contribute to naïve T cell movement.

In this study, we investigate the role of IL-7 and CCL21 in regulating metabolism and migration of naïve T cells. We find that IL-7 and CCL21 regulate metabolism via different pathways; IL-7 increases glycolysis while CCL21 actually decreases oxidative phosphorylation. We also find a novel role for IL-7 in driving high speed T cell motility in LNs via JAK1 and JAK3 as well as STAT5, but not mTOR. These results suggest that the IL-7R and CCR7 both drive T cell movement but through regulation of separate metabolic pathways.

\section{Results}

\section{IL-7 and CCL21 differentially affect naïve T cell metabolism}

IL-7 and CCL21 are both produced by lymph node stromal cells and are key regulators of naïve T cell function, with IL-7 regulating cell survival and CCL21 driving T cell motility. We tested how IL-7R and CCR7 signaling affect T cell metabolic activity. We added IL-7 and/or CCL21 to CD4 or CD8 T cells isolated from lymph nodes and spleen of naïve C57BI/ 6 animals then assessed both mitochondrial oxygen consumption (OCR) (Fig. 1A) as well as glycolytic activity (Fig. 1B) using the Agilent Seahorse analyzer (20).

We found that IL-7 has no effect on oxidative respiration as measured by OCR on basal OXPHOS or OCR after treatment with FCCP (Fig. 1C, D, E; ${ }^{* *}=p<0.01 ; * \star *=p<0.001$ ). In contrast, CCL21 treatment decreased maximum respiratory capacity after FCCP treatment (Fig. 1D) as well as spare respiratory capacity (Fig. 1E), but had no effect on basal respiration (Fig. 1C). In an analysis of glycolysis, IL-7 treatment increased glycolysis (Fig. 1F), glycolytic capacity (Fig. 1G), and glycolytic reserve (Fig. 1H) as measured by ECAR. CCL21 had no effect on glycolysis (Fig. 1F, 1G, 1H). The effects of CCL21 on OXPHOS and IL-7 on glycolysis were independent of one another, as treatment of T cells with both CCL21 and IL-7 showed similar effects as treatment with IL-7 or CCL21 alone. We show data for CD8 T cells but found similar results for CD4 T cells (data not shown). These results demonstrate that IL-7 and CCL21 can independently regulate ATP production via separate pathways in CD4 and CD8 T cells.

\section{IL-7 regulates CCR7 expression but is dispensable for T cell homing to the LNs}

One metabolic need for naïve T cells is motility for homing into lymph nodes as well as moving within lymph nodes. As we found IL-7 to regulate ATP production via glycolysis in naïve CD4 and CD8 T cells, we asked whether IL-7R participated in naïve T cell homing to LNs. Because genetic deletion of IL-7R results in ablation of the naïve T cell pool, we perturbed IL-7R function using blocking antibodies to IL-7 and IL-7R. We isolated total GFP ${ }^{+}$splenocytes and incubate with anti-IL-7R antibody and then transferred IL-7R-blocked splenocytes into mice treated with anti-IL-7 antibody. After 4.5 hours, peripheral blood and secondary lymphoid organs (SLOs) were assessed for homing of specific T cell subsets as well as B cells 
to SLOs in the absence of IL-7/IL-7R signals. We measured the effect of IL-7R antibody blockade on T cell surface expression of IL-7R using flow cytometry. In the LNs and the spleen, anti-IL-7R-treated GFP ${ }^{+} T$ cells exhibited lower IL-7R expression in anti-IL-7-treated animals compared to isotype-treated animals (Fig. 2A-B; LN p = 0.0013, spleen $p=0.0005$ ). We then assessed homing of IL-7R-blocked T cells in anti-IL7 treated animals compared to isotype-blocked $T$ cells in isotype-treated animals. We found no significant difference in the number of IL-7/IL-7R-blocked T cells $\left(\mathrm{CD}^{+} \mathrm{GFP}^{+}\right)$or B cells $\left(\mathrm{CD} 19^{+} \mathrm{GFP}^{+}\right)$in SLOs, spleen or blood compared to isotype-treated animals (Fig. 2C-F). Homing of $\mathrm{GFP}^{+} \mathrm{CD} 4^{+}$and $\mathrm{CD} 8^{+} \mathrm{T}$ cell subsets to SLOs were similar relative to total $\mathrm{CD} 4^{+}$and $\mathrm{CD} 8^{+}$subsets (data not shown). These results show that total T cell migration to LNs is not changed in the absence of IL-7/IL-7R signaling.

A previous study implicated CCR7 in IL-7R responses, so we assessed CCR7 expression in IL-7/IL-7R blocked T cells (26). Cell surface staining showed transferred IL-7/IL-7R blocked T cells in the LNs and spleen expressed slightly lower CCR7 levels compared to T cells from isotype-treated mice. We saw a similar trend for $T$ cells from the spleen (Fig. $2 E-F ; L N p=0.0037$, spleen $p=0.0907$ ). These results indicate that while IL-7R signaling can modulate CCR7 expression, IL-7/IL-7R signaling is not required for T cell homing from blood into LNs.

\section{IL-7 promotes T cell motility in the LN, leading to decreased contacts with DCs}

Another key metabolic need in naïve T cells is rapid motility within lymph nodes to enhance dendritic cell interactions. We asked whether IL-7 might affect T cell motion within LNs using time-lapse two photon microscopy (2PM) of LN explants. Total $\mathrm{CD}^{+} \mathrm{T}$ cells were isolated from naïve Ubiquitin-GFP mice or from naïve C57BL/ 6 mice then labeled with CMTMR, and adoptively transferred into naïve C57BL/6 recipients. LNs were harvested one day later and imaged for a duration of up to 4 hours. Labeled naïve $T$ cells were visualized and tracked before and after addition of anti-IL-7 and anti-IL-7R antibodies.

T cells showed significantly reduced mean track speeds after $\sim 20$ minutes of IL-7/IL-7R inhibition by antibody addition (Fig. 3A, Video 1; median of before antibody addition $=6.7 \mu \mathrm{m} \mathrm{min}^{-1}$, median of after antibody addition $=4.8 \mu \mathrm{m} \mathrm{min}^{-1}, \mathrm{p}<0.0001$ ). After antibody addition, the arrest coefficient, or the percent of time a cell moves slower than $2 \mu \mathrm{m} \mathrm{min}^{-1}$, significantly increased (Fig. 3B; median of before experiments $=8.5$, median of after experiments $=20, p<0.0001$ ). We evaluated the effect of IL-7/IL-7R blockade on directional persistence using track straightness. Track straightness, as measured by a confinement ratio, did not change after antibody addition (Fig. 3C; median $=0.41, p=0.4169$ ), but the fraction of track time a T cell spends moving a distance of less than $5 \mu \mathrm{m}$ (idle time) was greater after antibody blockade (Fig. 3D; median of before experiments $=0.2334$, median of after experiments $=$ $0.3847, p=0.0184$ ). As a control, we treated with anti-CD28 antibodies which had no effect on $T$ cell speeds (data not shown). These data indicate that IL-7 promotes T cell motility in the LN, and that IL-7/IL7R inhibition dramatically decreases $T$ cell speed and displacement without changing the confinement or straightness patterns of $T$ cell tracks. 
One key role for rapid T cell motility is to facilitate T cell search for cognate antigen presented by DCs in the LN. We hypothesized that absence of IL-7R signaling leading to decreased T cell motility in vivo could decrease baseline T-DC interactions. We employed a computational approach to estimate the effect of IL7 blockade on the frequency of T-DC contacts. We used a computational model in which empirical T cell tracks were embedded in a simulated field with uniformly positioned "DC targets" to determine the ability of T cells to contact DCs (7). We first showed that T cells scan a smaller volume after IL-7R blockade, with T cells scanning a volume of approximately $7.7 \mu \mathrm{m}^{3} \mathrm{~s}^{-1}$ before IL-7R inhibition compared to $5.7 \mu \mathrm{m}^{3}$ $\mathrm{s}^{-1}$ after IL-7R antibody blockade (Fig. 3E; $\mathrm{p}=0.0001$ ). We then computationally determined how many contacts would be made by T cells with DCs with and without IL-7 signaling. We found that T cells make slightly fewer total contacts (Fig. 3F, $p=0.049$ ) with DCs and significantly fewer unique contacts (different DCs contacted) after IL-7/IL-7R blockade (Fig. 3G, $p<0.0001$ ), indicating IL-7-induced motility may be critical for $T$ cells to efficiently cover a larger search area and scan numerous separate DCs in search of potentially rare cognate antigen.

We experimentally confirmed the computational predictions by measuring whether IL-7R signaling affected T cell proximity to DCs in our 2PM LN explant model. We co-imaged T cells with DCs by labeling WT T cells with CMTMR and adoptively transferring labeled T cells into CD11C-YFP mice (21). Using 2PM to simultaneously visualize T cells and DCs, we measured the distance between T cell tracks and DCs in the LN before and after IL-7/IL-7R antibody blockade (Video 2). We found that T cells spent a greater proportion of individual track time closer to DCs prior to antibody blockade (Fig. 3H, median percent of track time within $5 \mu \mathrm{m}$ of DCs before treatment $=83 \%$, median after treatment $=45 \%, p=0.001$ ). These results suggest that high speed motility induced by IL-7R signaling can increase the likelihood of $T$ cell interaction with individual DCs within the LN.

Because IL-7R inhibition decreased T cell proximity to DCs, this raised the possibility that IL-7 may act to recruit T cells to DCs. We assessed whether DCs might directly recruit T cells via IL-7/IL-7R signaling by calculating whether T cells "turn" towards DCs with IL-7/IL-7R signaling. We determined whether T cells "turn" by calculating turning angles (TAs) of T cell tracks close to DCs (i.e. within $25 \mu \mathrm{m}$ ) and far from DCs (i.e. any part of track $\geq 25 \mu \mathrm{m}$ ) before and after IL-7/IL-7R antibody blockade. Smaller TAs close to DCs would indicate T cells are "attracted" to DCs. If IL-7/IL-7R could recruit T cells to DCs, we expected that blocking IL-7/IL-7R would result in an increase of TA towards $90^{\circ}$, decreasing recruitment. We found that before antibody blockade, TAs of T cells moving close to DCs were comparable to TAs of T cells moving far from DCs (Fig. 3l; median close $=75.31^{\circ}$, median far $=71.80^{\circ}, \mathrm{p}$ value $=0.1182$ ). After antibody blockade, TAs changed to a smaller angle, suggesting potential recruitment towards DCs only upon IL-7R inhibition (Fig. 3l; median close after $=78.79^{\circ}$, median far after $=59.20^{\circ}, \mathrm{p}$ value $<0.0001$ ). While TAs of T cells close to DCs were similar before and after antibody blockade (Fig. 3l; median close before $=75.31^{\circ}$, median close after $=78.79^{\circ}$, $\mathrm{p}$ value $=0.3617$ ), TAs of T cells after antibody blockade were smaller only for T cells far from DCs, suggesting that IL-7 actually acts to increase random motility rather than recruit T cells to move towards DCs. Our results suggest that IL-7 increases T cell encounters 
with DCs by promoting rapid T cell motility, which promotes scanning of many individual DCs within LNs leading to effective T cell sampling of DCs within lymph nodes.

\section{IL-7 effects on T cell motility are not mediated by mTOR activation but by JAK/STAT signaling}

mTOR complexes promote aerobic glycolysis in T cells, and IL-7 has been shown to activate mTOR (22, 23). As IL-7R regulates motility and glycolysis, we tested whether IL-7R signals via mTOR to influence naïve $T$ cell motility. To maintain a consistent system of perturbation within the lymph node to analyze motility rather than genetic ablation which may affect other aspects of $T$ cell function including $T$ cell development, we used a pharmacologic approach to inhibit mTOR with well described inhibitors of either mTORC1 inhibitor rapamycin or mTORC1 and mTORC2 inhibitor with PP242. We assessed T cell motility before and after rapamycin and PP242 treatment. Interestingly, inhibiting mTOR via PP242 or rapamycin resulted in a slight, but significant increase in naïve T cell motility (Fig. 4A left panel, median track speed mean before PP242 addition $=4.1 \mu \mathrm{m} \mathrm{min}^{-1}$, median track speed mean after PP242 addition $=5.4 \mu \mathrm{m}$ $\min ^{-1}, p<0.0001$; Fig. 4B right panel, median track speed mean before rapamycin addition $=3.0 \mu \mathrm{m} \mathrm{min}^{-}$ 1 , median track speed mean after rapamycin addition $=4.3 \mu \mathrm{m} \mathrm{min}^{-1}, \mathrm{p}=0.0058$ ). These data indicate that in naïve T cells, mTOR actually restrains T cell movement and does not act downstream of IL-7R to regulate $\mathrm{T}$ cell motility.

IL-7R signals via JAK1/3 and STAT 5 activation as well as mTOR resulting in survival and proliferation effects, so we investigated whether JAK/STAT pathways regulate T cell motility downstream of IL-7R (24). We utilized commercially available and well-studied inhibitors of the JAK/STAT pathway. We treated LNs with Ruxolitinib (Rux; pan-JAK inhibitor) to determine the effect of JAK inhibition on T cell motility in the $L N$ and image $T$ cells as previously described. Rux treatment resulted in a striking reduction in $T$ cell mean track speeds (Fig. 4C, median track speed of $8.9 \mu \mathrm{m} \mathrm{min}^{-1}$ before treatment compared to $5.6 \mu \mathrm{m}$ $\mathrm{min}^{-1}$ after Rux treatment, $\left.\mathrm{p}<0.0001\right)$. We then asked whether JAK3 was specifically involved in regulating $T$ cell motility by treating $L N s$ with Tofacitinib, a JAK3 inhibitor (25). Tofacitinib treatment resulted in a more modest, but still significant reduction in T cell track speeds (Fig. 4D, median track speed of $6.1 \mu \mathrm{m} \mathrm{min}^{-1}$ before treatment compared to $5.2 \mu \mathrm{m} \mathrm{min}^{-1}$ after Tofa treatment, $\mathrm{p}<0.0001$ ). These results show that JAKs are key effectors downstream of IL-7R signaling mediating $T$ cell motion in LNs.

Downstream of JAK phosphorylation, IL-7R signaling activates STAT5, which is crucial for long-term naïve T cell survival (26). To determine the effect of STAT5 on naïve T cell motility in the LN, we inhibited STAT5 using 2-[(4-oxo-4H-1-benzopyran-3-yl)methylene]hydrazide 3-pyridinecarboxylic acid, hereafter referred to as STAT5 inhibitor. Treatment of LN explants with STAT5 inhibitor resulted in a profound reduction in T cell track speeds within 25 minutes (Fig. 4E, median track speed $7.7 \mu \mathrm{m} \mathrm{min}^{-1}$ before treatment compared to $2.3 \mu \mathrm{m} \mathrm{min}^{-1}$ after treatment, $\left.\mathrm{p}<0.0001\right)$. STAT5 inhibition consistently caused a more pronounced reduction in motility than IL-7 and IL-7R inhibition or JAK inhibition, raising the possibility that multiple signals may activate STAT 5 to promote $T$ cell motility. These results demonstrate that JAK1/3 activation of STAT5 is necessary for T cell motility in the LN downstream of IL-7R. 


\section{IL-7R and CCR7 signaling converge to control T cell speed in the LN}

We assessed how IL-7R and CCR7 might converge on cytoskeletal pathways leading to T cell motility. Rho GTPases are established in many cell types as regulators of actin cytoskeleton reorganization leading to polarization and motility including in T cells downstream of CCR7 (27-29). Rho family activation is also required for STAT activity (30). We hypothesized that RhoA might also regulate T cell motion downstream of IL-7R. In agreement with this hypothesis, we found that IL-7R activation via IL-7 significantly activated RhoA in in vitro activated primary murine T cells as measured by GLISA similar to levels seen upon CCL21 activation (Fig. 4F, $\mathrm{p}=0.0114$ ). These results show that both IL-7R and CCR7 activate RhoA leading to high speed T cell motility.

We then directly assessed the interplay between CCR7 and IL-7R in regulating T cell motility. To test how IL-7R and CCR7 interact to drive T cell motion in vivo, we transferred CCR7 ${ }^{-/-} \mathrm{T}$ cells into recipient animals, then imaged LNs with 2PM before and after anti-IL-7 antibody addition as described previously. We found that $\mathrm{CCR}^{-/-} \mathrm{T}$ cells show approximately $50 \%$ reduction in T cell speed compared with WT T cells (Fig. 5A, $p<0.0001)$ in agreement with published literature and our own previous work $(9,10,31)$. $\mathrm{CCR}^{-/-} \mathrm{T}$ cells showed no change in mean speed after addition of anti-IL-7 treatment (Fig. 5B, $p=$ 0.6166). These results suggest CCR7 and IL-7R converge on a similar downstream pathway to control T cell movement.

\section{Discussion}

Recent work has identified key metabolic pathways that regulate multiple $T$ cell functions, including $T$ cell activation, differentiation, proliferation, and survival (4). However, little is known about what metabolic pathways regulate naïve $T$ cell movement. Naïve $T$ cell motility facilitates $T$ cell search for cognate antigen in the lymph node which is important to determine the timing of $\mathrm{T}$ cell priming. Here, we show a role for IL-7R in glycolysis and CCR7 in OXPHOS as well as high speed T cell motion in lymph nodes. Using computational modeling and confirming by experimental observation, we find that blocking IL-7R signaling decreases T cell movement in lymph nodes resulting in decreased proximity to DCs. Previous observations had demonstrated IL-7 is not required for T cell activation and proliferation in vitro, but is required for productive T cell proliferation in vivo (32). Our data suggest that IL-7 likely regulates T cell priming and proliferation not through direct effects on TCR signaling, but rather by mediating the ability of $T$ cells to move throughout the LN rapidly. We show that IL-7 does not recruit T cells to DCs as analyzed by turning angles of T cells near DCs. We and others have previously shown that T cells associate with the fibroblastic reticular network in lymph nodes to mediate high speed motility $(8,33,34)$. Combined, these data suggest that IL-7 and CCL21 from FRCs and stromal cells within the lymph node function together to promote rapid motility of T cells, resulting in enhanced interaction rates with DCs, improving the scanning efficiency of T cells in lymph nodes for new target DCs.

Our results confirm previous findings that IL-7R can regulate glycolysis in naïve T cells for ATP generation $(18,19)$. Interestingly, while naïve T cells are thought to predominantly utilize OXPHOS for metabolic 
needs, we find that IL-7R increases glycolytic ECAR and CCR7 independently decreases OXPHOS as shown by OCR in naïve CD8 and CD4 T cells. This suggests that for motility, OXPHOS may exert some inhibitory effect and that CCR7 may simultaneously decrease OXPHOS while IL-7R increases glycolysis for metabolic needs associated with motility. Our results are consistent with work showing that dendritic cells have been shown to utilize glycolysis to maintain cell shape and motility associated with CCR7 oligomerization (35).

Our findings suggest that IL-7R and CCR7 regulate motility in a convergent pathway, likely involving actin regulators and the JAK/STAT pathway. Additionally, IL-7R also directly regulates CCR7 expression, which may contribute to the role of IL-7R effects on T cell motility. Inhibition of T cell motility occurs within minutes of IL-7R inhibition by blocking antibodies. Thus, IL-7R may act directly to regulate $T$ cell motility through metabolic pathways, actin cytoskeleton, and through effects on CCR7. It is likely that both IL-7R and CCR7 signaling contribute to JAK/STAT activation, as CCR7 and IL-7R have both been shown to signal via the JAK/STAT pathway $(15,36)$. The STAT family of proteins has been shown to be activated by GPCRs and implicated in cancer cell migration via microtubules and integrins $(37,38)$. Previously, Pelletier et al. identified Rho GTPases as a link between GPCR signaling and STAT activation in smooth muscle cells (30), so the profound motility reduction after STAT5 inhibition may reflect an inhibition of both a $\mathrm{Ga}_{i}$-dependent (e.g. CCR7) and $\mathrm{Ga}_{i}$-independent (e.g. IL-7R) regulation of T cell motility in the LN.

We find that while JAK $1 / 3$ and STAT 5 are required for high speed T cell motility downstream of IL-7R, mTOR activity actually restrains T cell motility. This is surprising as mTOR is generally considered a regulator of glucose metabolism $(17,22)$. However, both mTOR complexes mTORC1 and mTORC2 have been shown to also regulate OXPHOS $(39,40)$. mTOR has been shown to control the actin cytoskeleton in multiple cell types including yeast, cancer cells, and Tregs (41-45). Thus, while mTOR can signal downstream of IL-7R in naïve T cells, our results suggest that rapid T cell motility may depend on CCR7 decrease in OXPHOS and mTOR with a simultaneous increase in glycolytic ATP generation through IL-7R signaling via JAK/STAT.

In addition to its obligate cytokine function in naïve T cells, IL-7R has been shown to play a role in driving disease phenotypes including solid tumors as well as T cell leukemias (46-48). We have identified a novel role for IL-7 in regulating rapid naïve T cell motility through regulation of glycolytic metabolism. Preferentially using glycolysis is a hallmark of cancer cell metabolism, and IL-7R-mediated glycolytic metabolism may be therapeutically exploitable in T cell leukemias. IL-7- and CCL21-induced motility is emphasized by a reduction in OXPHOS mediated by CCR7 signaling and a concomitant increase in glycolysis mediated by IL-7R, leading to enhanced T cell scanning of DCs. Our results shed new light on the metabolic requirements for naïve $T$ cell motility leading to effective $T$ cell responses.

\section{Materials And Methods}

\section{Mice and reagents}


C57BL/6 (Jackson Laboratories), B6. Ubiquitin-GFP (Jackson Labs, 004353), and B6.129P2(C)Ccr7tm1Rfor/J (Jackson Labs, 006621), and B6.Cg-Tg(Itgax-Venus)1Mnz/J (Jackson Labs, 008829) mice were used. All mice were maintained in a specific pathogen-free environment in barrier facilities at the University of New Mexico School of Medicine in Albuquerque, NM, and conform to the principles outlined by the Animal Welfare Act and the National Institutes of Health guidelines and approved by the IACUC animal use committee. Males and females were used at between 8-20 weeks. Splenocytes from mice were stimulated with anti-CD3 (145-2C11) and anti-CD28 (PV-1) antibodies. Anti-CD3-APC (eBioscience, Cat 17-0031-83), anti-CD4-FITC (eBioscience, Cat 11-0041-82), anti-CD8-APC-Cy7 (eBioscience, Cat 47-0081-82), anti-CD197-PE (BD Biosciences, Cat 560682), and anti-CD127-PE Cy7 (eBioscience, Cat 25-1271-82) were used for staining T cell populations from total splenocytes. All experimental protocols were approved by the IACUC animal use committee at UNM Health Sciences Center in accordance with relevant guidelines and regulations (IACUC protocol \#s: 18-200797-B-HSC; 16200497-HSC; 19-200892-HSC). All animal work was performed and reported according to ARRIVE guidelines.

\section{Metabolic assessment of $\mathrm{T}$ cells}

CD4 and CD8 T cells were isolated from spleen and lymph nodes of C57BI/6 animals using the Miltenyi CD4 and CD8 isolation kits (Miltenyi Biotec). Cells were stimulated with $300 \mathrm{ng} / \mathrm{ml}$ murine CCL21 (Peprotech) and/or $100 \mathrm{mg} / \mathrm{ml}$ murine IL-7 (Peprotech) for 3 hours at $37 \mathrm{oC}$. Cells were then assessed for metabolism using the Agilent Seahorse SF Cell Mito Stress Kit per manufacturer instructions for OCR readings and the Agilent Seahorse SF Cell Glyco Stress Kit for glycolysis. After Seahorse assays were performed, cells were fixed with $4 \%$ formalin and stained with DAPI and counted on Celllnsight CX7 for cell normalization.

\section{GTP-bound RhoA quantitation}

RhoA activation was measured in in vitro activated T cells with a G-LISA kit (BK124, Cytoskeleton, Inc.). Cells were treated with CCL21 $1 \mu \mathrm{g} \mathrm{mL}^{-1}$, IL-7 $10 \mathrm{ng} \mathrm{mL}^{-1}$, IL-7 $100 \mathrm{ng} \mathrm{mL}^{-1}$, or untreated for 1-3 minutes prior to cell lysis. Equal numbers of cells in each group were lysed using kit-provided cell extraction buffer. Lysates were equalized to $25 \mu \mathrm{g}$ per well using lysis buffer. Anti-RhoA primary antibody incubation followed by an HRP-conjugated secondary antibody incubation were performed for detection of GTP-bound RhoA. The signal was measured by absorbance at $490 \mathrm{~nm}$.

\section{T cell homing}

On days -3 and -1 , recipient mice were administered $250 \mu \mathrm{g}$ anti-IL-7 or isotype antibody in PBS intraperitoneally. Single cell suspensions from $\mathrm{GFP}^{+}$murine $\mathrm{LNs}$ and spleens were treated with anti-IL-7R or isotype antibody $\left(10 \mu \mathrm{g} \mathrm{mL}^{-1}\right)$ for 10 minutes and adoptively transferred $\left(3.0 \times 10^{7}\right.$ cells $)$ into recipient mice on day 0 . After a homing period of 4.5 hours, the recipient mice were sacrificed and peripheral blood, spleen, and LNs were harvested. Single cell suspensions from the tissues were measured by flow cytometric analysis. 


\section{Flow cytometry}

Single cell suspensions from murine LNs and spleens were stained with conjugated antibodies (listed in Mice and reagents) according to standard protocols. Data was acquired using a BD LSR Fortessa (BD) and analyzed using FlowJo (FlowJo, LLC). Flow cytometric analysis of primary murine cells consisted of gating on lymphocytes population from FSC x SSC, gating on CD3 + or CD19 + events, then gating on GFP + events. These populations were then assessed for CCR7 + events and IL-7R + events.

\section{Two-photon microscope setup}

LNs were imaged using two microscope setups. Zeiss LSM510 META/NLO microscope (25x objective): A Chameleon Ti:Sapphire (Coherent) laser was tuned to either $820 \mathrm{~nm}$ for excitation of CMTMR or $850 \mathrm{~nm}$ for simultaneous excitation of YFP and CMTMR or GFP excitation. ZEN software (Zeiss) was used to acquire time-lapse z-stacks with duration 15-45 minutes. Z-step increment: $4 \mu \mathrm{m}$. Prairie Technologies Ultima Multiphoton microscope from Bruker (20x objective): A Ti-Sapphire (Spectra Physics) laser was tuned to either $820 \mathrm{~nm}$ for excitation of CMTMR or $850 \mathrm{~nm}$ for simultaneous excitation of YFP and CMTMR or GFP excitation. Prairie View 5.4 software (Prairie Technologies) was used to acquire timelapse z-stacks with duration 15-45 minutes. Z-step increment: $4 \mu \mathrm{m}$.

\section{Two-photon microscopy (2PM) of intact LNs}

Mice were sacrificed and harvested LNs were transferred to an Chamlide AC-B25 chamber (Live Cell Instrument) containing oxygen superfused DMEM (Gibco, 21063-045) and maintained at $5 \% \mathrm{CO}_{2}$ and $37^{\circ} \mathrm{C}$. During imaging, LNs were stabilized to the coverslip using slice anchors (Warner Instruments, SHD42/10 WI 64-1421).

\section{T cell tracking and DC quantitation}

T cells were tracked using semi-automated Spots function in Imaris (Bitplane) with manual correction. Distances to DCs were measured by creating Surfaces of DC channel fluorescence, performing a distance transformation on tracked Spots with respect to the outside of the Surface. For each Spot, the output of the Intensity Center for the distanced transformed channel is the distance to the outside of the closest Surface. MATLAB (Mathworks) was used to calculate the percentage of each track within $5 \mu \mathrm{m}$ of a Surface. For T cell turning angles close and far to DCs, tracks were split into two groups: tracks with no coordinates 25 um farther than a DC, and tracks with coordinates 25 um or farther from a DC. Turning angles (TAs) were computed by finding the magnitude of two vectors, $v_{1}$ and $v_{2}$, from 3 coordinates and determining the cosine of the turning angle using the following equation: 


$$
\cos (T A)=\frac{\overrightarrow{\left(v_{1}\right) \cdot\left(v_{2}\right)}}{\left|\overrightarrow{\left(v_{1}\right)}\right|\left|\left(v_{2}\right)\right|}
$$

\section{T cell track idle time calculation}

The fraction of time a T cell track spent constrained was performed using the following steps. It was assumed that each 2PM video frame $i$ occurs at time $t_{i}$, with time $t_{C}$ being the constrained time, $t_{C}=t_{i_{2}}-t_{i_{1}}$

if the distance between the T cell time $t_{i_{1}}$ and all time frames between $i_{1}$ and $i_{2}$ is less than the specified constrained distance, $5 \mu \mathrm{m}$

$$
\left|\overrightarrow{x_{i}}-\overrightarrow{x_{i_{1}}}\right|<5 \mu m, i=i_{1}, \ldots i_{2} \text {.) }
$$

Time was not counted as time constrained until the time difference $t_{i_{2}}-t_{i_{1}}$ was greater than 100 seconds. This was done because even fast-moving $T$ cells remained close to their initial positions in subsequent frames. Once a T cell exited the $5 \mu \mathrm{m}$ radius, e.g. at frame $i_{3}$, distances and constrained times were tracked from $x_{i_{3}}$ and $t_{i_{3}}$.

\section{T cell track volume calculations}

To calculate the volume covered by each T cell track, microscope fields were divided into voxels of 2.5 $\mu \mathrm{m}^{3}$. The distances between each $\mathrm{T}$ cell and the centers of its surrounding voxels were calculated. The volume of the cube was included in the track volume calculation if the distance between the T cell and the center of the voxel was less than the radius of the cell. T cells were assumed to have a radius of 5 $\mu \mathrm{m}$. Voxel volumes were only counted once per T cell track in the event a T cell traversed the same voxel multiple times. The calculation-eligible voxel volumes were summed and divided by the total time the T cell was tracked.

\section{T-DC contacts model}

Simulated DCs were assumed to have a radius of $5 \mu \mathrm{m}$. Simulated DCs were distributed uniformly in a $360 \times 360 \times 360 \mu \mathrm{m}$ cube and occupied $5 \%$ of the total volume. Empirical T cell tracks were embedded in the cube at the tracks' field coordinates. 200 different DC distributions were created for each set of T cell tracks and the results from each distribution were averaged. A T-DC contact was counted if the distance between a T cell center and a DC center was less than $10 \mu \mathrm{m}$. Unique contacts were defined as a DC 
being counted only once for a particular T cell track, and the total contact definition allowed for counting the DC as many times as a particular T cell track entered the threshold distance $(10 \mu \mathrm{m})$.

\section{Ethics Statement}

All experimental research reported here were performed with approval of required IACUC and Biosafety committees per relevant guidelines and regulations. The authors have no conflicts of interest to declare.

\section{Declarations}

\section{Acknowledgements}

Thanks to the UNM Cancer Center Fluorescence Microscopy Facility (P30-CA119100) and the UNM Center for Brain Recovery and Repair Pre-Clinical Core (P20-GM109089-01A1) for facilitating 2 photon microscopy work. We also thank Dr. John Weaver and Sharina Desai, Technical Directors of the Core Facility of the Autophagy, Inflammation, and Metabolism Center of Biomedical Research Excellence (P20GM121176). This work was supported by funding from the following: NIH 1R01AI097202 (JLC), the Spatiotemporal Modeling Center (P50 GM085273), the Center for Evolution and Theoretical Immunology 5P20GM103452 (JLC), NIH 5 T32 Al007538-19 (JRB), an Institutional Development Award (IDeA) from NIGMS P20GM103451 (DJT) and RL5GM118969 (DJT); institutional support from dedicated health research funds from UNM SOM (JLC), Women in Science Award from UNM, DARPA/AFRL FA8650-18-C6898 (JLC), and Stephanie Ruby pre-doctoral fellowship from UNM SOM MGM department (JRB). JLC is a member of the Autophagy, Inflammation, and Metabolism COBRE at the UNM HSC (P20GM121176). Core resource support from P30-CA119100 and P20-GM109089-01A1.

\section{Ethics Statement}

Research reported here were performed with approval of all required IACUC and Biosafety protocols. The authors have no conflicts of interest to declare.

\section{Data Availability}

All data included in the manuscript are available by request to the corresponding author.

\section{Author Contributions}

J.R.B and J.L.C. wrote the paper. J.R.B, J.L.C., and P.M. designed experiments. J.L.C. and J.R.B created figures. J.R.B., R.G., and S.R.O. performed experiments. J.R.B. and D.J.T. performed data analysis. All authors provided input into interpretation of data and writing of the paper.

\section{References}


1. O'Neill, L. A., Kishton, R. J., and Rathmell, J. (2016) A guide to immunometabolism for immunologists. Nat Rev Immunol 16, 553-565

2. Pearce, E. L. (2010) Metabolism in T cell activation and differentiation. Curr Opin Immuno/ 22, 314320

3. van der Windt, G. J., and Pearce, E. L. (2012) Metabolic switching and fuel choice during T-cell differentiation and memory development. Immunol Rev 249, 27-42

4. Geltink, R. I. K., Kyle, R. L., and Pearce, E. L. (2018) Unraveling the Complex Interplay Between T Cell Metabolism and Function. Annu Rev Immuno/ 36, 461-488

5. Kastenmuller, W., Torabi-Parizi, P., Subramanian, N., Lammermann, T., and Germain, R. N. (2012) A spatially-organized multicellular innate immune response in lymph nodes limits systemic pathogen spread. Cell 150, 1235-1248

6. Gerner, M. Y., Torabi-Parizi, P., and Germain, R. N. (2015) Strategically localized dendritic cells promote rapid T cell responses to lymph-borne particulate antigens. Immunity 42, 172-185

7. Fricke, G. M., Letendre, K. A., Moses, M. E., and Cannon, J. L. (2016) Persistence and Adaptation in Immunity: T Cells Balance the Extent and Thoroughness of Search. PLoS Comput Biol 12, e1004818

8. Krummel, M. F., Bartumeus, F., and Gerard, A. (2016) T cell migration, search strategies and mechanisms. Nat Rev Immunol 16, 193-201

9. Worbs, T., Mempel, T. R., Bolter, J., von Andrian, U. H., and Forster, R. (2007) CCR7 ligands stimulate the intranodal motility of T lymphocytes in vivo. The Journal of experimental medicine 204, 489-495

10. Asperti-Boursin, F., Real, E., Bismuth, G., Trautmann, A., and Donnadieu, E. (2007) CCR7 ligands control basal $\mathrm{T}$ cell motility within lymph node slices in a phosphoinositide 3-kinase-independent manner. The Journal of experimental medicine 204, 1167-1179

11. Hauser, M. A., and Legler, D. F. (2016) Common and biased signaling pathways of the chemokine receptor CCR7 elicited by its ligands CCL19 and CCL21 in leukocytes. J Leukoc Bio/ 99, 869-882

12. Woolf, E., Grigorova, I., Sagiv, A., Grabovsky, V., Feigelson, S. W., Shulman, Z., Hartmann, T., Sixt, M., Cyster, J. G., and Alon, R. (2007) Lymph node chemokines promote sustained T lymphocyte motility without triggering stable integrin adhesiveness in the absence of shear forces. Nat Immuno/ 8, 10761085

13. Link, A., Vogt, T. K., Favre, S., Britschgi, M. R., Acha-Orbea, H., Hinz, B., Cyster, J. G., and Luther, S. A. (2007) Fibroblastic reticular cells in lymph nodes regulate the homeostasis of naive T cells. Nat Immuno/ 8, 1255-1265

14. Onder, L., Narang, P., Scandella, E., Chai, Q., Iolyeva, M., Hoorweg, K., Halin, C., Richie, E., Kaye, P., Westermann, J., Cupedo, T., Coles, M., and Ludewig, B. (2012) IL-7-producing stromal cells are critical for lymph node remodeling. Blood 120, 4675-4683

15. Crawley, A. M., Vranjkovic, A., Faller, E., McGuinty, M., Busca, A., Burke, S. C., Cousineau, S., Kumar, A., Macpherson, P. A., and Angel, J. B. (2014) Jak/STAT and PI3K signaling pathways have both common and distinct roles in IL-7-mediated activities in human CD8+ T cells. J Leukoc Bio/ 95, 117127

Page $13 / 25$ 
16. Fry, T. J., and Mackall, C. L. (2005) The many faces of IL-7: from lymphopoiesis to peripheral T cell maintenance. J Immunol 174, 6571-6576

17. Chi, H. (2012) Regulation and function of mTOR signalling in T cell fate decisions. Nat Rev Immunol $12,325-338$

18. Rathmell, J. C., Farkash, E. A., Gao, W., and Thompson, C. B. (2001) IL-7 enhances the survival and maintains the size of naive T cells. J Immunol 167, 6869-6876

19. Jacobs, S. R., Michalek, R. D., and Rathmell, J. C. (2010) IL-7 is essential for homeostatic control of T cell metabolism in vivo. J Immunol 184, 3461-3469

20. Buck, M. D., O'Sullivan, D., Klein Geltink, R. I., Curtis, J. D., Chang, C. H., Sanin, D. E., Qiu, J., Kretz, O., Braas, D., van der Windt, G. J., Chen, Q., Huang, S. C., O'Neill, C. M., Edelson, B. T., Pearce, E. J., Sesaki, H., Huber, T. B., Rambold, A. S., and Pearce, E. L. (2016) Mitochondrial Dynamics Controls T Cell Fate through Metabolic Programming. Cel/ 166, 63-76

21. Lindquist, R. L., Shakhar, G., Dudziak, D., Wardemann, H., Eisenreich, T., Dustin, M. L., and Nussenzweig, M. C. (2004) Visualizing dendritic cell networks in vivo. Nat Immuno/ 5, 1243-1250

22. Salmond, R. J. (2018) mTOR Regulation of Glycolytic Metabolism in T Cells. Front Cell Dev Biol 6, 122

23. Allgauer, A., Schreiner, E., Ferrazzi, F., Ekici, A. B., Gerbitz, A., Mackensen, A., and Volkl, S. (2015) IL-7 Abrogates the Immunosuppressive Function of Human Double-Negative $T$ Cells by Activating Akt/mTOR Signaling. J Immunol 195, 3139-3148

24. Ghoreschi, K., Laurence, A., and O'Shea, J. J. (2009) Janus kinases in immune cell signaling. Immunol Rev 228, 273-287

25. Changelian, P. S., Flanagan, M. E., Ball, D. J., Kent, C. R., Magnuson, K. S., Martin, W. H., Rizzuti, B. J., Sawyer, P. S., Perry, B. D., Brissette, W. H., McCurdy, S. P., Kudlacz, E. M., Conklyn, M. J., Elliott, E. A., Koslov, E. R., Fisher, M. B., Strelevitz, T. J., Yoon, K., Whipple, D. A., Sun, J., Munchhof, M. J., Doty, J. L., Casavant, J. M., Blumenkopf, T. A., Hines, M., Brown, M. F., Lillie, B. M., Subramanyam, C., Shang-Poa, C., Milici, A. J., Beckius, G. E., Moyer, J. D., Su, C., Woodworth, T. G., Gaweco, A. S., Beals, C. R., Littman, B. H., Fisher, D. A., Smith, J. F., Zagouras, P., Magna, H. A., Saltarelli, M. J., Johnson, K. S., Nelms, L. F., Des Etages, S. G., Hayes, L. S., Kawabata, T. T., Finco-Kent, D., Baker, D. L., Larson, M., Si, M. S., Paniagua, R., Higgins, J., Holm, B., Reitz, B., Zhou, Y. J., Morris, R. E., O'Shea, J. J., and Borie, D. C. (2003) Prevention of organ allograft rejection by a specific Janus kinase 3 inhibitor. Science 302, 875-878

26. Seki, Y., Yang, J., Okamoto, M., Tanaka, S., Goitsuka, R., Farrar, M. A., and Kubo, M. (2007) IL-7/STAT5 cytokine signaling pathway is essential but insufficient for maintenance of naive CD4 T cell survival in peripheral lymphoid organs. J Immunol 178, 262-270

27. Mrass, P., Oruganti, S. R., Fricke, G. M., Tafoya, J., Byrum, J. R., Yang, L., Hamilton, S. L., Miller, M. J., Moses, M. E., and Cannon, J. L. (2017) ROCK regulates the intermittent mode of interstitial T cell migration in inflamed lungs. Nature Communications 8, 1010 
28. Pernis, A. B. (2009) Rho GTPase-mediated pathways in mature CD4+ T cells. Autoimmun Rev 8, 199203

29. Ridley, A. J. (2015) Rho GTPase signalling in cell migration. Curr Opin Cell Bio/ 36, 103-112

30. Pelletier, S., Duhamel, F., Coulombe, P., Popoff, M. R., and Meloche, S. (2003) Rho family GTPases are required for activation of Jak/STAT signaling by $\mathrm{G}$ protein-coupled receptors. Mol Cell Biol 23, 13161333

31. Letendre, K., Donnadieu, E., Moses, M. E., and Cannon, J. L. (2015) Bringing statistics up to speed with data in analysis of lymphocyte motility. PLoS One 10, e0126333

32. Saini, M., Pearson, C., and Seddon, B. (2009) Regulation of T cell-dendritic cell interactions by IL-7 governs T-cell activation and homeostasis. Blood 113, 5793-5800

33. Tasnim, H., Fricke, G. M., Byrum, J. R., Sotiris, J. O., Cannon, J. L., and Moses, M. E. (2018) Quantitative Measurement of Naive T Cell Association With Dendritic Cells, FRCs, and Blood Vessels in Lymph Nodes. Front Immuno/ 9, 1571

34. Miller, M. J., Hejazi, A. S., Wei, S. H., Cahalan, M. D., and Parker, I. (2004) T cell repertoire scanning is promoted by dynamic dendritic cell behavior and random $\mathrm{T}$ cell motility in the lymph node. Proc Natl Acad Sci U S A 101, 998-1003

35. Guak, H., Al Habyan, S., Ma, E. H., Aldossary, H., Al-Masri, M., Won, S. Y., Ying, T., Fixman, E. D., Jones, R. G., McCaffrey, L. M., and Krawczyk, C. M. (2018) Glycolytic metabolism is essential for CCR7 oligomerization and dendritic cell migration. Nat Commun 9, 2463

36. Garcia-Zepeda, E. A., Licona-Limon, I., Jimenez-Solomon, M. F., and Soldevila, G. (2007) Janus kinase 3-deficient T lymphocytes have an intrinsic defect in CCR7-mediated homing to peripheral lymphoid organs. Immunology 122, 247-260

37. Teng, Y., Ross, J. L., and Cowell, J. K. (2014) The involvement of JAK-STAT3 in cell motility, invasion, and metastasis. JAKSTAT 3, e28086

38. Silver, D. L., Naora, H., Liu, J., Cheng, W., and Montell, D. J. (2004) Activated signal transducer and activator of transcription (STAT) 3: localization in focal adhesions and function in ovarian cancer cell motility. Cancer Res 64, 3550-3558

39. Liu, C., Chapman, N. M., Karmaus, P. W., Zeng, H., and Chi, H. (2015) mTOR and metabolic regulation of conventional and regulatory T cells. J Leukoc Bio/ 97, 837-847

40. de la Cruz Lopez, K. G., Toledo Guzman, M. E., Sanchez, E. O., and Garcia Carranca, A. (2019) mTORC1 as a Regulator of Mitochondrial Functions and a Therapeutic Target in Cancer. Front Oncol 9, 1373

41. Kishore, M., Cheung, K. C. P., Fu, H., Bonacina, F., Wang, G., Coe, D., Ward, E. J., Colamatteo, A., Jangani, M., Baragetti, A., Matarese, G., Smith, D. M., Haas, R., Mauro, C., Wraith, D. C., Okkenhaug, K., Catapano, A. L., De Rosa, V., Norata, G. D., and Marelli-Berg, F. M. (2017) Regulatory T Cell Migration Is Dependent on Glucokinase-Mediated Glycolysis. Immunity 47, 875-889 e810

42. Liu, L., and Parent, C. A. (2011) Review series: TOR kinase complexes and cell migration. J Cell Biol $194,815-824$ 
43. Jacinto, E., Loewith, R., Schmidt, A., Lin, S., Ruegg, M. A., Hall, A., and Hall, M. N. (2004) Mammalian TOR complex 2 controls the actin cytoskeleton and is rapamycin insensitive. Nat Cell Biol 6, 11221128

44. He, Y., Li, D., Cook, S. L., Yoon, M. S., Kapoor, A., Rao, C. V., Kenis, P. J., Chen, J., and Wang, F. (2013) Mammalian target of rapamycin and Rictor control neutrophil chemotaxis by regulating $\mathrm{Rac} / \mathrm{Cdc} 42$ activity and the actin cytoskeleton. Mol Biol Cell 24, 3369-3380

45. Wang, J., Lu, Y., Wang, J., Koch, A. E., Zhang, J., and Taichman, R. S. (2008) CXCR6 induces prostate cancer progression by the AKT/mammalian target of rapamycin signaling pathway. Cancer Res 68, 10367-10376

46. Park, S. L., Lee, E. J., Kim, W. J., and Moon, S. K. (2014) p27KIP1 is involved in ERK1/2-mediated MMP-9 expression via the activation of NF-kappaB binding in the IL-7-induced migration and invasion of 5637 cells. Int J Onco/ 44, 1349-1356

47. Silva, A., Laranjeira, A. B., Martins, L. R., Cardoso, B. A., Demengeot, J., Yunes, J. A., Seddon, B., and Barata, J. T. (2011) IL-7 contributes to the progression of human T-cell acute lymphoblastic leukemias. Cancer Res 71, 4780-4789

48. Zenatti, P. P., Ribeiro, D., Li, W., Zuurbier, L., Silva, M. C., Paganin, M., Tritapoe, J., Hixon, J. A., Silveira, A. B., Cardoso, B. A., Sarmento, L. M., Correia, N., Toribio, M. L., Kobarg, J., Horstmann, M., Pieters, R., Brandalise, S. R., Ferrando, A. A., Meijerink, J. P., Durum, S. K., Yunes, J. A., and Barata, J. T. (2011) Oncogenic IL7R gain-of-function mutations in childhood T-cell acute lymphoblastic leukemia. Nat Genet 43, 932-939

\section{Figures}


Figure 1

A
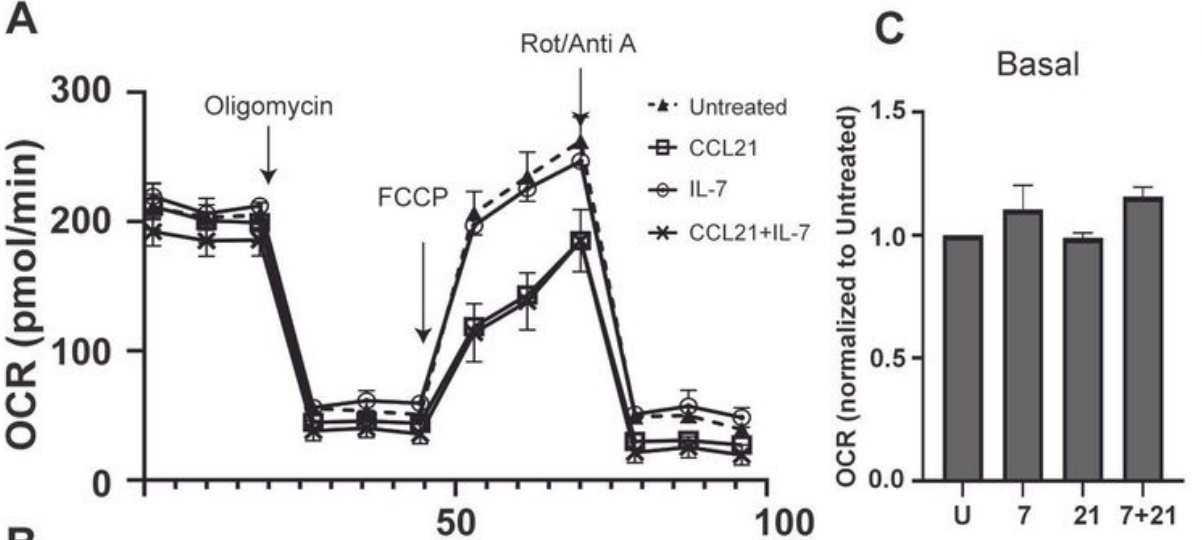

Dax Resp Capacity

Epare Resp Capacity
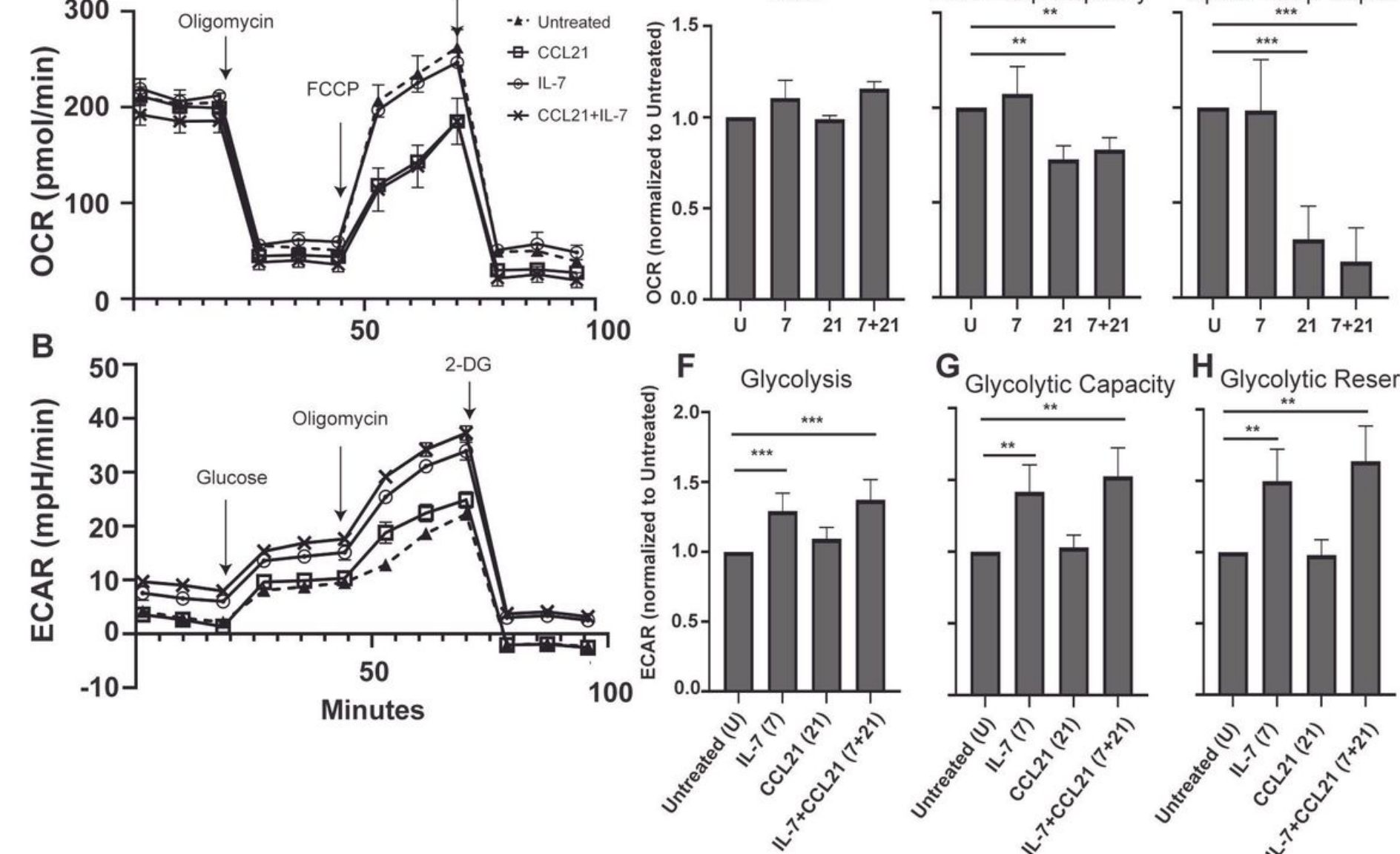

G Glycolytic Capacity

$\mathbf{H}_{\text {Glycolytic Reserve }}$
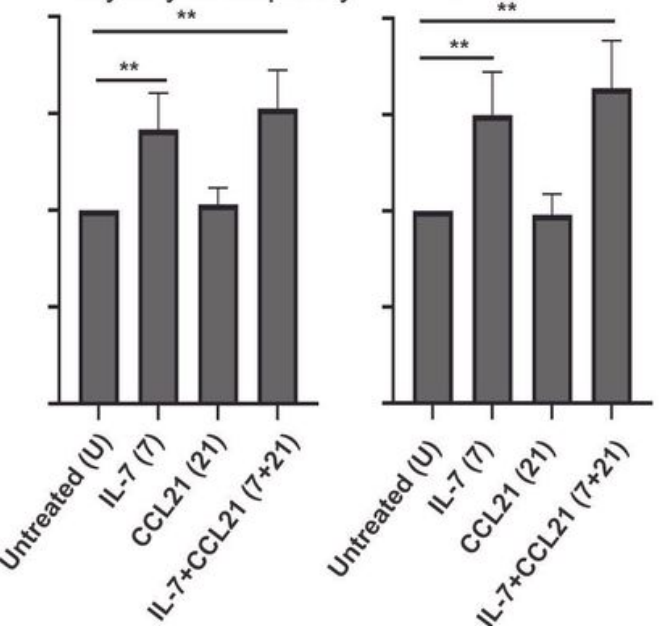

Figure 1

IL-7 and CCL21 differentially regulate metabolic pathways in naïve T cells.

CD8 T cells were isolated from lymph nodes and spleens of C57BI/6 animals and simulated with IL-7 at $100 \mathrm{mg} / \mathrm{ml}$ and/or CCL21 at 300ng/ $\mathrm{ml}$ for 2 hours, then assessed for OCR using the MitoStress kit (A, C-

E) or GlycoStress kit (B, F-H). Raw data (A, B) were analyzed with Agilent Seahorse software and each sample was normalized to the cell numbers and fold change calculated by normalizing to baseline readings from the untreated sample from each experiment. Data shown are the combined results from 4 independent experiments with at least 2-3 wells each. Students t-test is shown with $* \star *=p<0.001$; $\star *=p<0.01$. 
Figure 2

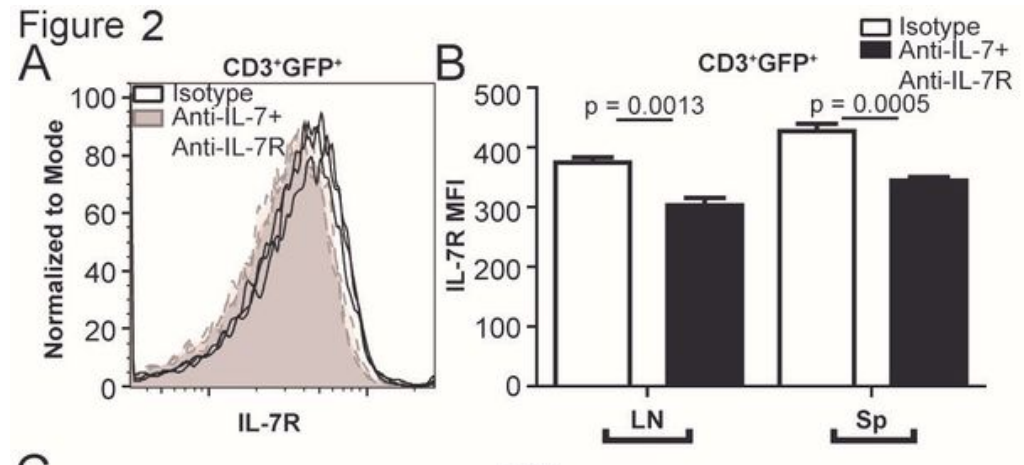

C
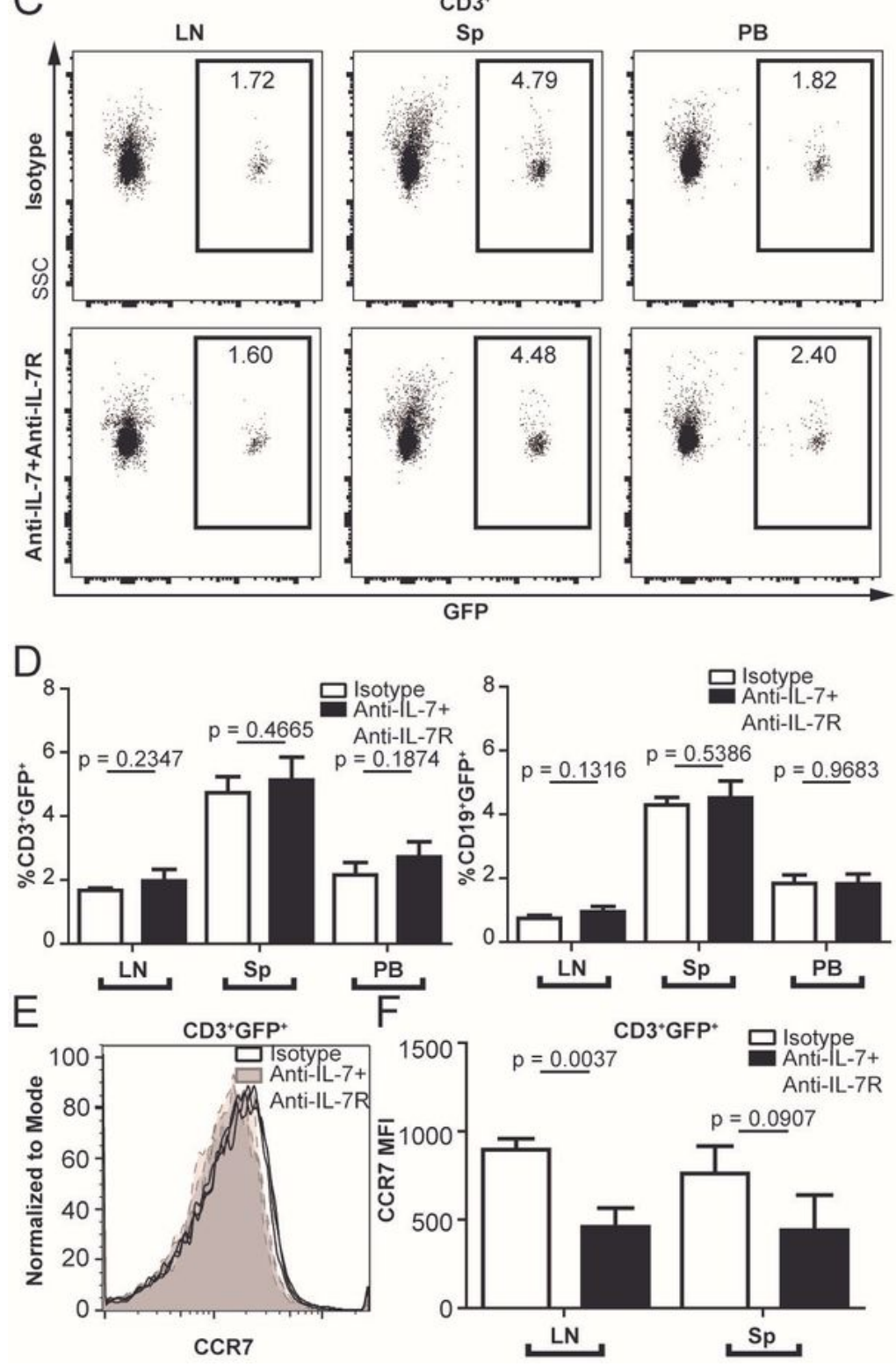

\section{Figure 2}

IL-7 regulates CCR7 expression but not homing of naïve T cells to lymph nodes.

Naïve mice received either anti-IL-7 or isotype control via IP injection on days -3 and -1 . On day 0 , GFP+ splenocytes were treated with isotype antibody or anti-IL-7R $\left(10 \mu \mathrm{g} \mathrm{mL}^{-1}\right)$ antibody and adoptively transferred into the antibody-treated (called "Anti-IL-7 + Anti-IL-7R") or isotype-treated (called "Isotype") 
mice. After 4.5 hours, recipient mice were sacrificed and GFP+ T cells in LNs, spleen, and blood were counted using flow cytometry. Data for isotype-treated animals are in white bars and anti-IL-7/IL-7Rtreated animals in black.

(A) Histogram of MFI of IL-7R expression in CD3+GFP+ population in LN. (B) IL-7R MFI of CD3+GFP+ population in $L N$ and spleen. Two-tailed student's $T$ test $p$ values are shown. (C) Representative gating strategy for GFP+ cells in CD3+ population for LN, spleen, and peripheral blood for both anti-IL-7 + anti-IL$7 R$ treated mice and isotype-treated mice. (D, left) Percent of CD3+GFP+ events counted in LN, spleen, and peripheral blood. Two-tailed student's T test are indicated. (D, right) Percent of CD19+GFP+ events counted in LN, spleen, and peripheral blood. Two-tailed student's T test are shown. (E) Histogram of MFI of CCR7 expression in CD3+GFP+ population in the LN. (F) MFI of CCR7 expression in CD3+GFP+ population in LN and spleen in antibody-treated mice (mean MFI value across 3 samples $=896$ ) and isotype-treated mice (mean MFI value across 3 samples $=459$ ). Two-tailed student's T Test is shown.

A, C, E: Data from a single representative experiment is shown. B, D, F: Data are from 2 independent experiments with 3 mice in each condition (total $n=6$ mice per condition). 
Figure 3
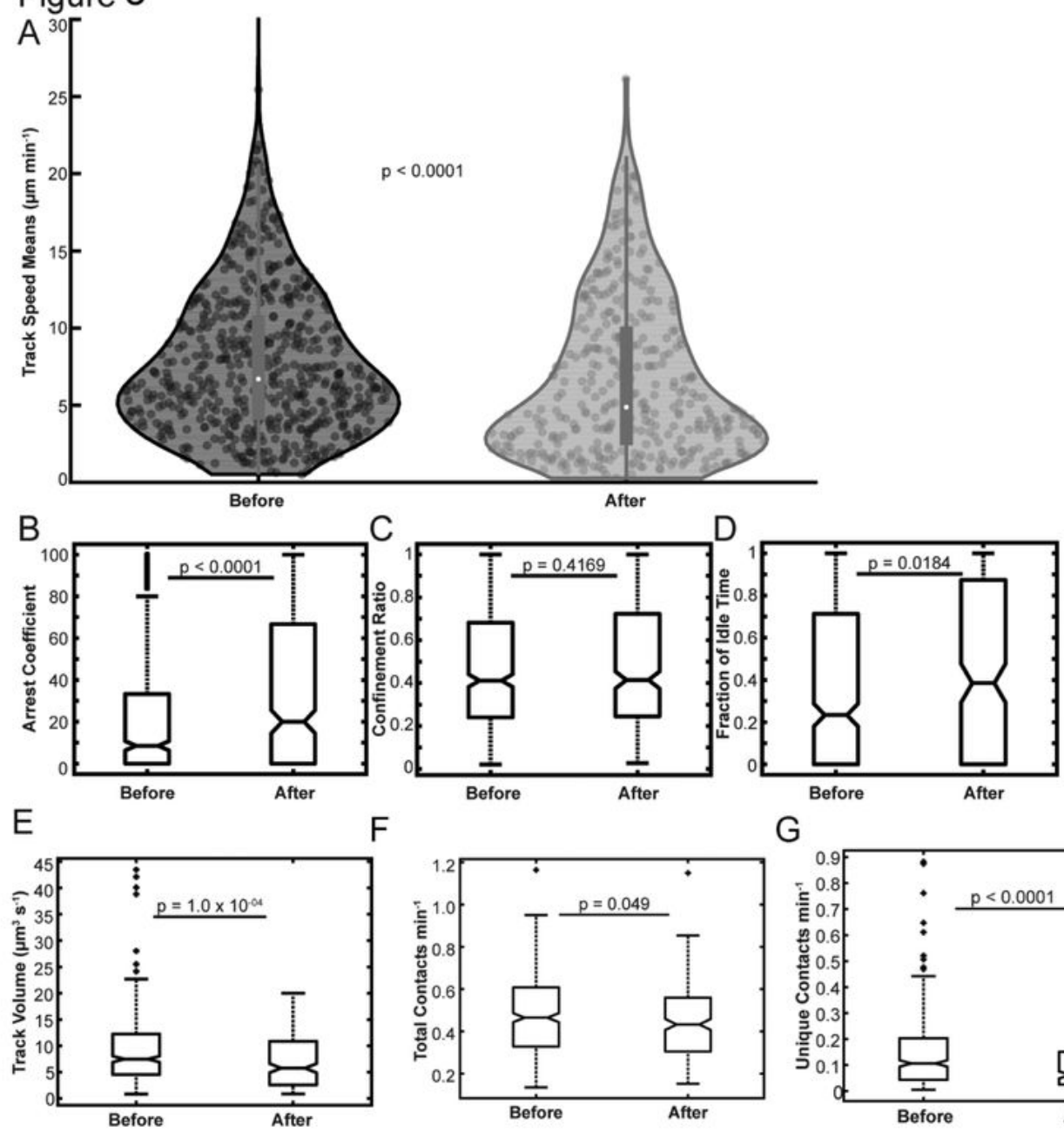

$\mathrm{F}$

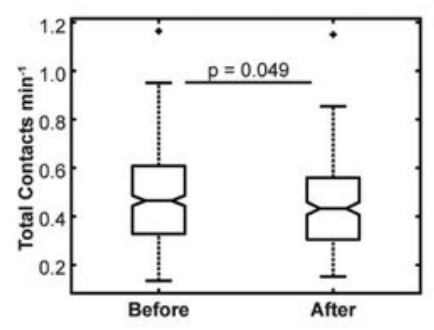

G
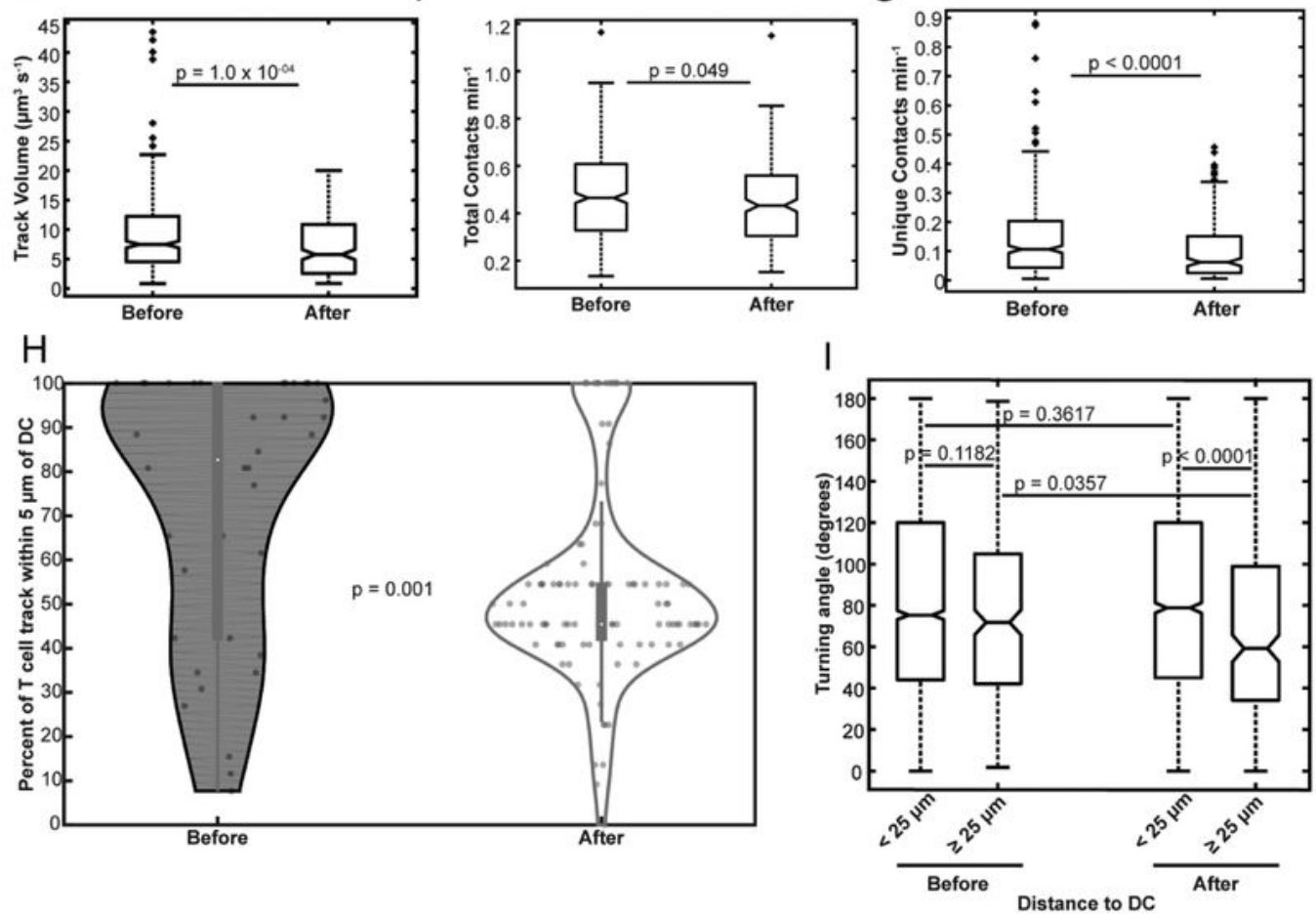

\section{Figure 3}

IL-7 is required for high speed T cell motility in lymph nodes and motility enhances potential T-DC interactions.

$\mathrm{CD} 3+\mathrm{T}$ cells were isolated from GFP+ mice and adoptively transferred into naïve mice, or T cells were isolated from C57BI/6 mice and labeled with CMTMR and then adoptively transferred into naïve mice. 
The following day, LNs were harvested, kept intact, and superfused with media during imaging by 2PM. Partway through imaging, antibodies against IL-7 and IL-7R were added to the superfused media and imaging continued. Each time-lapse z-stack was acquired for 15-45 minutes. Data are pooled from 3 experiments on 3 days, imaging multiple lymph nodes from a single mouse in each experiment. $T$ cells in videos were tracked with semi-automated tracking with manual editing, with no filtering for minimum displacement (Imaris; Bitplane, Inc.). Before $n=554$ T cells, After $n=355$ T cells.

(A) Violin plots of mean track speeds of individual T cells before (black) and after (grey) addition of antiIL-7 and anti-IL-7R. Median (open circle; Before $=6.7 \mu \mathrm{m} \mathrm{min}^{-1}$, After $=4.8 \mu \mathrm{m} \mathrm{min}^{-1}$ ), interquartile range (grey bars) and full range (grey line) are depicted. The shape of the violin is the kernel density estimate of the mean track speeds. Mann Whitney $p$ value $<0.0001$. (B) Arrest coefficient (proportion of time a T cell track is $<2 \mu \mathrm{m} \mathrm{min}^{-1}$; Mann Whitney $\mathrm{p}$ value $<0.0001$ ), (C) confinement ratio (track displacement divided by track length; Mann Whitney $p$ value $=0.4169)$, and $(D)$ fraction of track time moving fewer than $5 \mu \mathrm{m}$ for before and after antibody addition (Mann Whitney $p$ value $=0.0184$ ). (B-D) Median (black line), 95\% confidence interval around median (boundaries of notch), interquartile range (box), full range (whisker), and outliers (crosses) are shown. (E-G). Computational modeling predicts IL-7 regulated motility affects T cell scanning of DCs. A computational model of the volume of the lymph node with expected dendritic cell numbers as described in Materials and Methods. (E) Volume covered by T cells was calculated from T cells tracks imaged as described in Fig 3A-D and Materials and Methods. Volume was calculated based on actual tracks of CD3+ T cells imaged by 2PM before and after IL-7/IL-7R inhibition. (F) Total contacts and $(G)$ unique contacts made by $T$ cells were calculated using computational model of the lymph node and T cell interaction with simulated DCs performed as described in Materials and Methods. Contacts were calculated (contacts $\mathrm{min}^{-1}$ ) before and after addition of IL-7/IL-7R antibodies. T cell tracks were fed into a simulator to quantify interactions with "DC targets". (F) Total Contacts measured how many times a T cell interacted with any simulated DC during the run. Total Contacts: median before treatment $=0.46$ contacts $\mathrm{min}^{-1}$, Total Contacts median after treatment $=0.43$ contacts $\mathrm{min}^{-1}$. (G) Unique Contacts calculated how many different DCs were contacted by $T$ cells over the full simulation. Unique Contacts: median before treatment $=0.11$ contacts $\mathrm{min}^{-1}$. Unique Contacts median after treatment $=0.06$ contacts $\mathrm{min}^{-1}$. Total contacts Mann Whitney test $\mathrm{p}$ value $=0.049$. Unique contacts Mann Whitney test $p$ value $<0.0001$. $(\mathrm{H}-\mathrm{I}) \mathrm{CD} 3+\mathrm{T}$ cells were isolated from GFP+ mice and adoptively transferred into naïve mice, or $\mathrm{T}$ cells were isolated from C57BI/6 mice and labeled with CMTMR and then adoptively transferred into CD11C-YFP naïve mice. The following day, LNs were harvested, kept intact, and superfused with media during imaging by 2PM. Partway through imaging, antibodies against IL-7 and IL-7R were added to the superfused media and imaging continued. Each time-lapse z-stack was acquired for 15-45 minutes. Data are pooled from 3 experiments on 3 days, imaging multiple lymph nodes from a single mouse in each experiment. T cells in videos were tracked with semi-automated tracking with manual editing, with no filtering for minimum displacement (Imaris; Bitplane, Inc.). T cells from lymph nodes originating from CD11c-YFP mice were analyzed for the percent of track time within $5 \mu \mathrm{m}$ of DC $(\mathrm{H})$. T cell tracks were also divided into tracks close to DCs $(<25 \mu \mathrm{m})$ and far from DCs $(\geq 25 \mu \mathrm{m})$ and their respective track turning angles were calculated (I). 
Figure 4

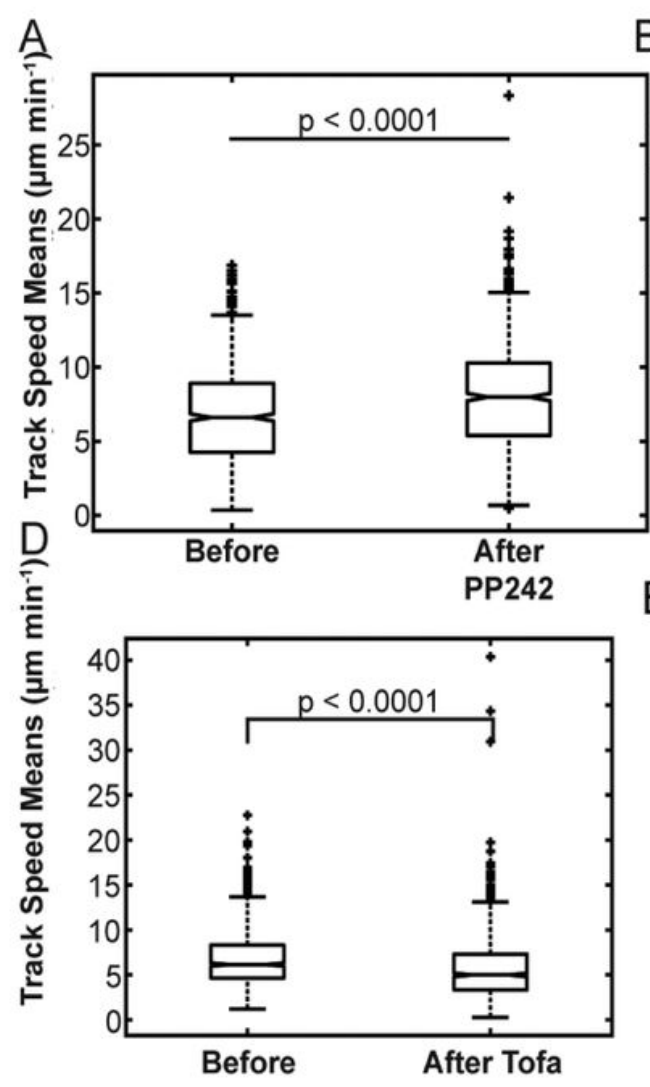

B

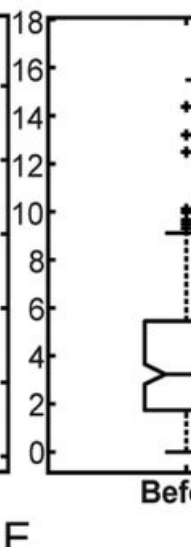

C

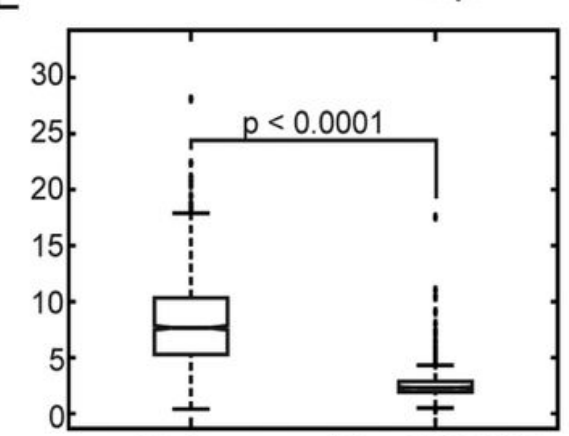

Before

$p<0.0001$

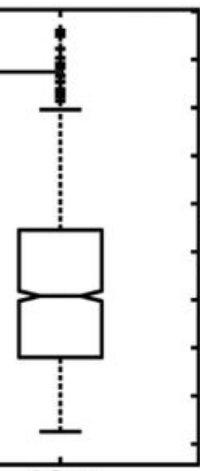

After

Rapa

After STAT5 inh

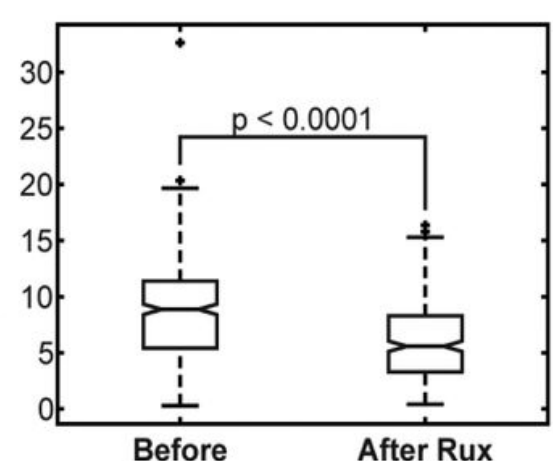

$\mathrm{F}$

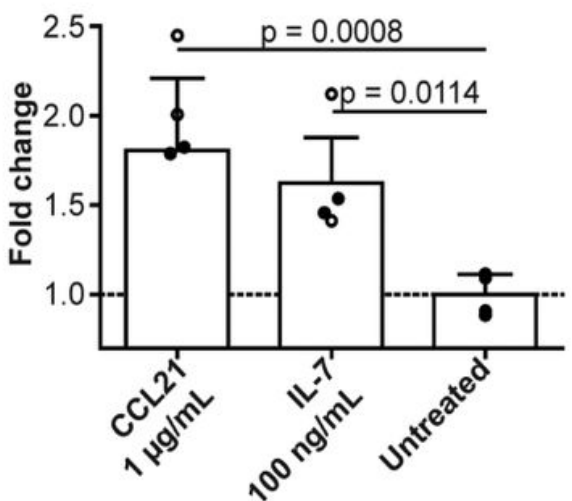

Figure 4

JAK/STAT signaling, but not mTOR, regulates T cell movement in LNs.

$\mathrm{CD} 3+\mathrm{T}$ cells were isolated from GFP+ mice and adoptively transferred into naïve mice, or T cells were isolated from C57BI/6 mice and labeled with CMTMR and then adoptively transferred into naïve mice. The following day, LNs were harvested, kept intact, and superfused with media during imaging by 2PM. Part way through imaging, PP242 (A), Rapamycin (B), Ruxolitinib (C), Tofacitinib (D), or STAT5 inhibitor (E) were added to the superfused media and imaging continued. Each time-lapse z-stack was acquired for 15-45 minutes. T cells in videos were tracked with semi-automated tracking with manual editing, with no filtering for minimum displacement (Imaris; Bitplane, Inc.). (A) T cell track speed means before ( $\mathrm{n}=$ $255)$ and after $(n=214)$ addition of PP242 $(1 \mu \mathrm{M})$. Median track speed mean before PP242 addition = $4.1 \mu \mathrm{m} \mathrm{min}^{-1}$, median track speed mean after PP242 addition $=5.4 \mu \mathrm{m} \mathrm{min}^{-1}$. Mann Whitney test $\mathrm{p}$ value $<0.0001$. (B) T cell track speed means before $(n=132)$ and after $(n=143)$ addition of rapamycin (100 $n g$ $\left.\mathrm{mL}^{-1}\right)$. Median track speed mean before rapamycin addition $=3.0 \mu \mathrm{m} \mathrm{min}^{-1}$, median track speed mean after rapamycin addition $=4.3 \mu \mathrm{m} \mathrm{min}^{-1}$. Mann Whitney test $\mathrm{p}$ value $=0.0058$. (C) $\mathrm{T}$ cell track speeds before and after addition of Jak inhibitor Ruxolitinib $(1 \mu \mathrm{M})$, Tofacitinib $(1 \mu \mathrm{M}$; D), or STAT5 inhibition (50 $\mu \mathrm{M}$; E). (C) Before Rux addition, median track speed mean $=8.9 \mu \mathrm{m} \mathrm{min}^{-1}(\mathrm{n}=408$ tracks). After Rux 
addition, median track speed mean $=5.6 \mu \mathrm{m} \mathrm{min}^{-1}(\mathrm{n}=287$ tracks $)$. Tracks were pooled from 2 separate experiments on 2 different days. Mann Whitney test $p$ value $<0.0001$. (D) Before Tofa addition, median track speed mean $=6.1 \mu \mathrm{m} \mathrm{min}^{-1}(n=1027$ tracks $)$. After Tofa addition, median track speed mean $=4.9$ $\mu \mathrm{m} \mathrm{min}{ }^{-1}$ (1092 tracks). Tracks were pooled from 3 separate experiments on 3 different days. Mann Whitney test $p$ value $<0.0001$. (E) Before STAT5 inh addition, median track speed mean $=7.7 \mu \mathrm{m} \mathrm{min}^{-1}(\mathrm{n}$ $=1749$ tracks). After STAT 5 inh addition, median track speed mean $=, 2.3 \mu \mathrm{m} \mathrm{min}^{-1}(\mathrm{n}=695$ tracks $)$. Tracks were pooled from 2 separate experiments on 2 different days. Mann Whitney test $p$ value < 0.0001. (F) GTP-bound RhoA in response to CCL21 $(1 \mu \mathrm{g} / \mathrm{mL})$, IL-7 $(10 \mathrm{ng} / \mathrm{mL})$ or untreated media as measured by G-LISA 2 minutes after addition of cytokines. Data representative of 4 experiments. Twotailed student's T test performed on data from CCL21 treatment ( $p$ value $=0.0008)$ and IL-7 treatment $(p$ value $=0.0114$ ) relative to untreated control. 
Figure 5

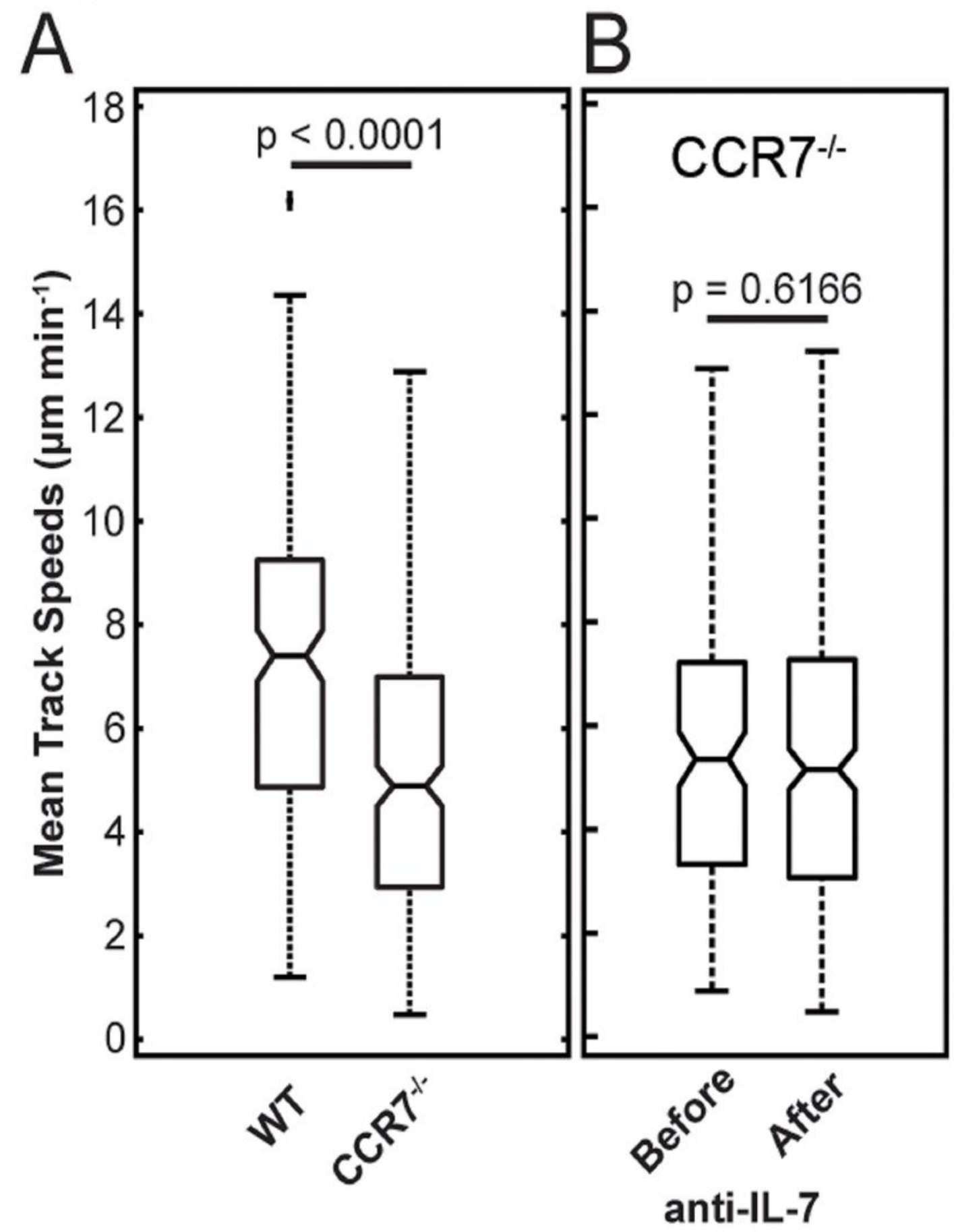

Figure 5

CCR7 and IL-7R function together to induce T cell motility.

CD3+ $\mathrm{T}$ cells were isolated from $\mathrm{C} 57 \mathrm{BI} / 6$ mice or $\mathrm{CCR} 7^{-1-}$ mice and labeled with $\mathrm{CMTMR}$, then adoptively transferred into naïve mice. The following day, LNs were harvested, kept intact, and superfused with 
media during imaging by 2PM. Partway through imaging, antibody against IL-7 was added to the superfused media and imaging continued. Each time-lapse z-stack was acquired for 15-45 minutes.

(A) Wild-type T cell mean track speeds $(n=199)$ relative to $C C R 7^{-/-}$T cell mean track speeds $(n=263)$. WT median $=7.4 \mu \mathrm{m} \mathrm{min}^{-1}, \mathrm{CCR}^{-/-}$median $=4.9 \mu \mathrm{m} \mathrm{min}^{-1}$. Mann Whitney test $\mathrm{p}$ value $<0.0001$. (B) CCR7 ${ }^{-1}$ T cell mean track speeds before $(n=137)$ and after $(n=279)$ anti-IL-7 antibody addition (10

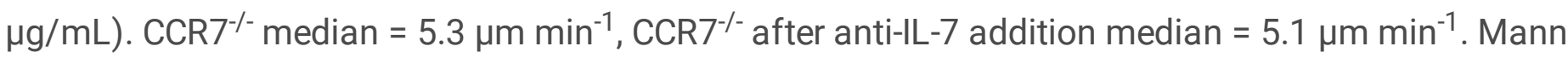
Whitney test $\mathrm{p}$ value $=0.6166$.

\section{Supplementary Files}

This is a list of supplementary files associated with this preprint. Click to download.

- Video1.mov

- Video2.mov 